\title{
A MÚSICA COMO FONTE REPRESENTATIVA DE INFORMAÇÃO: O CASO DA FONOTECA SATYRO DE MELLO NO CENTUR/FCPTN
}

\section{LA MÚSICA COMO UNA FUENTE REPRESENTATIVA DE LA INFORMACIÓN: EL CASO DE LA FONOTECA SATYRO MELLO EN CENTUR FCPTN}

\author{
Jetur Lima de Castro* \\ Alessandra Nunes de Oliveira**
}

\section{RESUMO}

Introdução: Ao se considerar a música como fonte interpretativa de informação.

Objetivo: Discute a importância da música como aspecto representativo na Fonoteca Satyro de Mello e como processo social e informacional.

Metodologia: Trata-se de uma pesquisa exploratória de base bibliográfica e documental.

Discussões: Apresenta a Fonoteca Satyro de Mello como instrumento de representação cultural e a música como fonte informativa no contexto social do bibliotecário.

Conclusões: Finaliza relatando a experiência que o bibliotecário precisa ter para desempenhar seu papel de mediador e agente cultural na Fonoteca Satyro de Mello.

Palavras-chave: Fonoteca. Música. Cultura. Informação. Bibliotecário.

\section{INTRODUÇÃO}

Desde o início da civilização, a humanidade vem buscando diversas formas de se comunicar sobre os acontecimentos históricosociais. Considerando sua plena participação nos processos de aprendizagem, no desenvolvimento da escrita, desenhos e formas de

* Graduando em Biblioteconomia pela Universidade Federal do Pará (UFPA). E-mail: jetur.er@gmail.com.

* Graduanda em Biblioteconomia pela Universidade Federal do Pará (UFPA). E-mail: alessandranunesoliveira@gmail.com. 
representações de signos. Nesta lógica, consideramos que cada indivíduo instaura seu próprio modo de pensar, buscando continuamente comunicar e informar sobre o meio em que vive.

Neste contexto, Miranda (2006, p. 103) em sua compreensão situa que "[...] grupos distintos de pessoas têm diferentes necessidades e hábitos de busca de informação, bem como estilos diferentes de processar a informação." Nesta abordagem, contextualizamos, compreender a configuração da informação, no sentido de que ela está inserida em diferentes suportes e nas diversas formas de utilidade, e das relações humana, no qual Oliveira (2005, p. 19) considera a informação como "[...] um fenômeno tão amplo que abrange todos os aspectos da vida em sociedade."

Com características diversas de comunicação e diálogo compreensivo, os indivíduos se dispõem de uma disparidade incomensurável para expressar suas ideias e se informar. Do mesmo modo, comunicar e manter um ato reflexivo entre os atores coletivos. Neste contexto, analisamos que essa expressão de ideias pode ser ponderada, nos seres sociais quando se encontram em contato com a música.

A música por sua vez, significa uma expressão, cultural artística incorporada pelos seres humanos, desde a Antiguidade. Tornou-se uma das formas de informar e expressar acontecimentos e representá-los artisticamente. Já que ela é um conjunto de palavras em grande sintonia com melodias, tornando-se significativa de acordo com o tempo e espaço dos seres e seus acontecimentos.

A música recorre em nós seres humanos, desde os primórdios, atravessa nosso cotidiano por meio de diferentes maneiras, em diversos públicos que se identificam com composições. É notório, para qualquer pessoa conseguir viver sem utilizá-la. Para Nietzsche (2001, p. 11) "Sem a música a vida seria um erro."

Assim sendo, situamos a música como "[...] signo que compreende duas ideias - uma é a idéia da coisa que representa, e 
outra, a ideia da coisa representada - e a natureza do signo consiste em excitar a segunda pela primeira." (NÖTH, 1995, p. 43). Desta forma, cogitou-se em pensar na importância da música com aspecto representativo, em algumas instâncias no processo social e tal como processo de informação. Para isto, a pesquisa buscou este foco no espaço da Fonoteca Satyro de Mello.

O objetivo do estudo é compreender a Fonoteca Satyro de Mello como instrumento de representação social que media a música através do seu acervo discos de vinil "Long Play" (LP), sendo uma grande fonte de informação musical para preservação cultural e artística, da Biblioteca Pública Arthur Viana.

Por conseguinte, consideramos esta pesquisa de cunho exploratório com base bibliográfica e documental. Desta forma, Gil (2002) afirma que a pesquisa exploratória proporciona maior familiaridade com o problema ao explicitá-lo e pode envolver tanto o levantamento bibliográfico como entrevistas com pessoas experientes no problema pesquisado. Em outras palavras, o estudo exploratório, tem por objetivo conhecer a variável de estudo tal como se apresenta, seu real significado e o contexto onde se insere.

Pressupõe-se que o comportamento humano é mais bem compreendido no contexto social onde ocorrem (QUEIRÓZ, 1992). Assim, buscou-se maior conhecimento sobre o problema para torná-lo mais explícito, e, assim "[...] aumentar a familiaridade do pesquisador com um ambiente, fato ou fenômeno, para a realização de uma pesquisa futura mais precisa, ou modificar e clarificar conceitos." (MARCONI; LAKATOS, 2006, p. 171).

Nesta lógica, posicionamos que foi feita uma visita a Fonoteca Satyro de Mello, para pesquisar seu acervo e sua mediação com o público-alvo. Sendo assim, o estudo é relevante, por mostrar a importância da Fonoteca Satyro de Mello como instrumento de representação social e cultural, principalmente da música como fonte 
informativa no contexto social e o bibliotecário como agente dessas informações.

A partir disto, a análise em questão está baseada em diversas leituras que conceituam a música com representação social, como em Le Coadic (1996, p. 5) que aborda a informação como "[...] um conhecimento inscrito (gravado) sob a forma escrita, oral ou audiovisual [...] um fenômeno tão amplo que abrange todos os aspectos da vida em sociedade." Blacking (2007, p. 201) na qual considera que o "[...] fazer 'musical' é um tipo especial de ação social que pode ter importantes conseqüências para outros tipos de ação social."

Retalhando os conceitos, através dos referenciados teóricos para demonstrar que a informação está inserida nos diversos suportes, entre eles, a música, por expressar-se em variados contextos. E até mesmo, mostrar como o bibliotecário tem fundamental importância como agente cultural nas ações que envolvem a mediação no seu ambiente de trabalho (MELO; VIEIRA, 2012).

Desta maneira, o estudo finaliza relatando a aprendizagem a experiência revisitada da Fonoteca Satyro de Mello, na qual se buscou entender como o bibliotecário de referência desempenha seu papel de mediador e agente cultural neste ambiente, visando a reflexão como importante ação na mediação da informação e a informação como fonte essencial de informação para preservação da memória.

\section{A MÚSICA COMO FONTE "REPRESENTATIVA" DA INFORMAÇÃO}

Ao explicitar sobre a música no contexto representativo, é preciso constatar que a informação está posta nos diversos suportes e diferentes meios como os documentos impressos, imagens que representam determinada ideia ou (signo). Segundo Deleuze (1992, p. 179) "Há um liame profundo entre os signos, o acontecimento, a vida, o 
vitalismo. É a potência de uma vida não orgânica, a que pode existir numa linha de desenho, de escrita ou de música."

Neste contexto, desenhando os indícios e retalhos, situamos que comunicar é se culturalizar e neste contexto ressaltamos a diversidade das coisas, na qual a (informação) se encontra inserida sobre os diferentes meios e suportes.

Com efeito,

A informação é um conhecimento inscrito (gravado) sob a forma escrita (impressa ou numérica), oral ou audiovisual. A informação comporta um elemento de sentido. É um significado transmitido a um ser consciente por meio de uma mensagem inscrita em um suporte espaço-temporal: impresso, sinal elétrico, onda sonora etc. (LE COADIC, 1996, p. 5).

Nos estudos de Deleuze (1992) a escrita torna a linguagem possível no homem, e lhe dá uma memória de palavras através dos (signos). A exemplo podem ser representados, através de placas de trânsito e os outdoors e até mesmo por objetos sonoros (Discos de vinil, Cd's, Dvd's, etc), dentre estes, situam na questão da música como uma ação representativa de informação.

Desta maneira, "Os signos não possuem significados até que estes sejam compartilhados, e assim tais processos tornam-se cruciais para a semiótica da música, como o produto sônico que fornece o foco para a análise." (BLACKING, 1981, p. 192).

Os [...] signos são de uma natureza qualquer e indiferentes ao seu suporte (ou não será o suporte que lhes é indiferente? O suporte é o corpo sem órgãos). Não obedecem a um plano, trabalham a todos os níveis e em todas as conexões; cada um fala a sua própria língua, e estabelece sínteses com outros, que são tanto mais directas em transversal quanto mais indirectas são na dimensão dos elementos. (DELEUZE; GUATTARI, 2004, p. 42). 
Com efeito, situamos que assim como existem diversas formas de informação, há também os diferentes atores que assimilam a informação, considerando sua realidade e seu contexto social, nas relações de aprendizagem. Deste modo, em Miranda (2006) os indivíduos têm diferentes determinações e tradições de busca de informação. Para Barros (2006, p. 12) "[...] a música é informação, pois modifica, transforma, comunica forma opiniões e representa conceitos."

A partir disso, apresentamos o contexto de que há vários atores que utilizam a música não só para o entretenimento, mais também para posicionar uma representação de informação no contexto social, dessa forma buscando conhecimento para aprender, ou até mesmo, se informar sobre uma determinada situação que represente um grupo ou sociedade.

A música não é apenas reflexiva, mas também gerativa, tanto como sistema cultural quanto como capacidade humana. Uma importante tarefa da musicologia é descobrir como as pessoas produzem sentido da "música", numa variedade de situações sociais e em diferentes contextos culturais, distinguindo entre as capacidades humanas inatas utilizadas pelos indivíduos nesse processo e as convenções sociais que guiam suas ações. (BLACKING, 2007, p. 201).

Deste modo, através da música torna-se possível entender a realidade social das pessoas que buscam informar e criar novos significados, através das composições, e de sua realidade social.

Toda música é um complexo que resulta da cultura à qual está inserida. Assim, toda música está referenciada à história, aos dados sociopolíticosestéticos, entre outros. Sendo assim, ressaltamos desde já: a música é informação. (VALENTE, 2005, p. 91). 
Com efeito, consideramos como exemplo o Hip Hop no Brasil, na qual retrata a realidade dos jovens da periferia, e onde utilizam do mecanismo da música, para emancipar-se ${ }^{1}$ de uma sociedade desigual, agindo a contracultura para mostrar, a integração social e mostram como são riscos de consciência crítica da situação em que vivem.

O hip hop passou a ser um dos principais porta-vozes contras agruras, desigualdade social, preconceito racial, falta de perspectiva, mas acima de tudo se tornou um agente catalisador da luta por justiça, igualdade, direito e reconhecimento, além de promover a integração social desses jovens [...]. Seus elementos artísticos (música, dança e artes plásticas) funcionam como condutores de informação, mobilizando os jovens e promovendo a consciência crítica da autonomia e da emancipação. (SILVA; ALBAGLI, 2012, p. 2).

Portanto, consideramos imprescindível a relação da informação como fonte de ações críticas através da música, pois tornou-se o caminho hábil para alcançar um conjunto de ações que são coletivas, levando à compreensão das letras como forma de entender o que está inserido em seu contexto.

Conforme Blacking (2007, p. 202):

As fontes de informação mais acessíveis sobre a natureza da "música" são encontradas, em primeiro lugar, na variedade de sistemas, estilos ou gêneros musicais que são atualmente realizados no mundo. Segundo, nas gravações históricas de partituras escritas, na iconografia e nas descrições de performances.

Assim sendo, situamos que é possível notar em outros estilos musicais como por exemplo no Funk, "[...] composições que retratam a realidade social vivida na periferia [...]" (AQUINO; SILVA JÚNIOR, 2012,

1 "A emancipação tem a ver com a libertação em relação à parcialidade que, pelo fato de não resultarem da causalidade da natureza ou das limitações do próprio entendimento, derivam, de certa forma, de nossa responsabilidade [...]." (HABERMAS, 1993, p. 99, grifo nosso). 
p. 257). Relata a vida social nas favelas, como taxada socialmente de vido a forma de expressão, visualizada nas composições de vários artistas.

Deste modo, deve se usar a "Autorreflexão [...] percepção sensível e emancipação, compreensão imperativa e libertação da dependência dogmática numa mesma experiência." (HABERMAS, 1987, p. 228). Para conceber a realidade e emancipar-se do mundo que chamamos de objetivo (razão instrumental)2.

Apresentamos a compreensão de uma composição do artista $\mathrm{Dj}$ Malboro, relacionada ao contexto social na música "som de preto" o cantor infere no sentido autor reflexivo: A sociedade para a gente não dá valor, só querem nos criticar pensam que somos animais. Desta forma, situamos que através de um pequeno trecho de uma música é possível obter a questão real que o cantor quer nos alertar.

Desta forma, constituímos que "A música quando bem trabalhada desenvolve o raciocínio, criatividade e outros dons e aptidões, por isso, deve-se aproveitar está tão rica atividade educacional dentro das salas de aula." (ONGARO; SILVA; RICCI, 2006, p. 2). A música como fonte representativa de informação não está apenas nas letras de fatos sociais, mas também na educação, para uma a aprendizagem de forma mais dinâmica.

É perceptível que assim como os livros são utilizados para a aprendizagem, à música também tem o poder de ensinar e informar de uma maneira (emancipatória).

\footnotetext{
2 As ciências empírico-analíticas exploram a realidade na medida em que esta se manifesta no raio da atividade instrumental; enunciados nomológicos acerca desse domínio do objeto estão assim presos, de acordo com seu sentido imanente, a um determinado contexto de aplicação; eles apreendem a realidade em vista de uma disponibilidade técnica que, em condições específicas, é sempre e em toda parte possível (HABERMAS, 1987, p. 216-217).
} 


\section{A FONOTECA SATYRO DE MELLO COMO ESPAÇO DE INFORMAÇÃO E REPRESENTAÇÃO MUSICAL}

De acordo com o Houaiss (2010, p. 367), Fonoteca significa "Coleção de documentos sonoros (discos, fitas etc.) local onde se conserva essa coleção." Significado este, que é possível ser compreendido na Fonoteca Satyro de Mello.

Porquanto, clarificamos que esse espaço se constitui com instrumento de ação cultural em Belém do Pará. Na qual, foi fundada em Junho de 1987, tornando-se a primeira da Amazônia e a segunda mais antiga do Brasil. Localizada no segundo andar da Biblioteca Pública de Belém do Pará, Arthur Vianna. Realiza o armazenamento e a organização de discos de vinil e a mediação cultural em seu espaço.

Deste modo, a Fonoteca Satyro de Mello faz seu trabalho com a informação, juntamente com a difusão cultural, abrigando um dos maiores acervos discográficos o segundo maior do Brasil, com $35 \mathrm{mil}$ vinis catalogados e mais de $1.300 \mathrm{~cd}$ 's, contando com videocassetes, partituras e CD-ROM. O Acervo aos vinis foram adquiridos por meio de doações, o primeiro acervo foi comprado, logo quando foi inaugurada a Fonoteca em 1987, pelo colecionador Carioca Ricardo Pereira, descoberto pelo poeta João de Jesus Paes Loureiro. 
Imagem 1: Faixa da Fonoteca Satyro de Mello

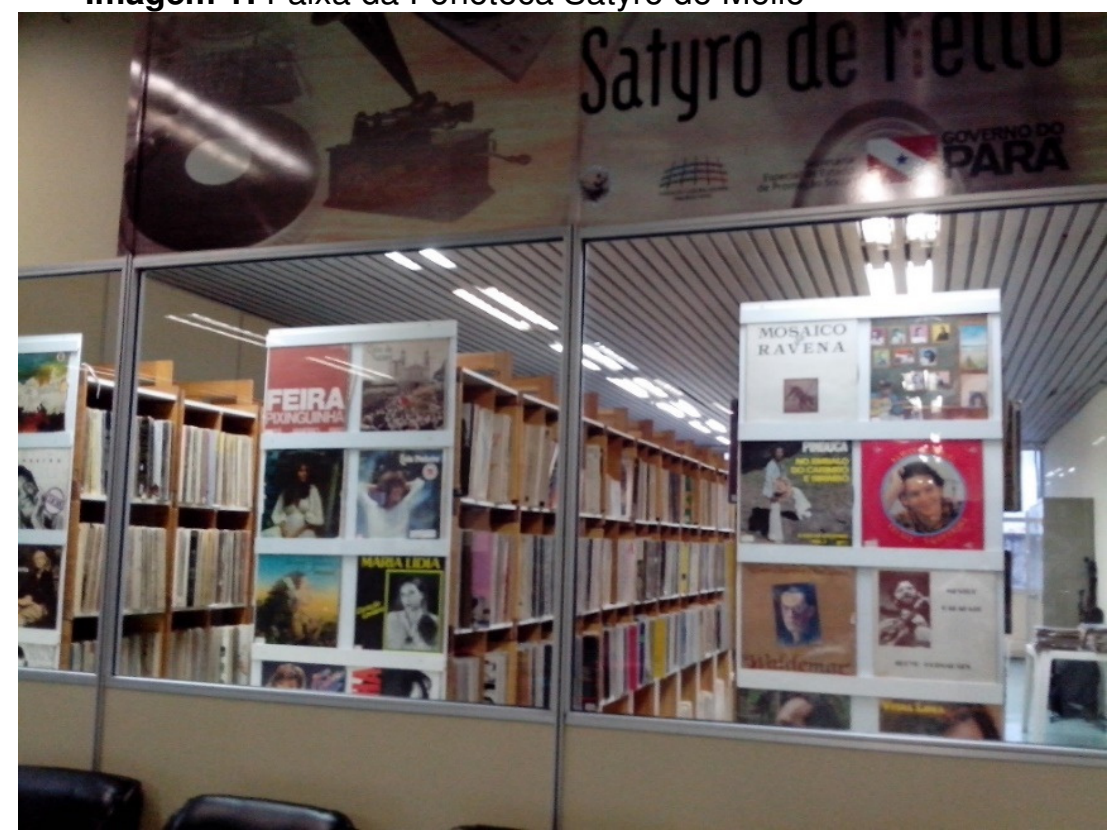

Fonte: Dados da pesquisa.

A Fonoteca recebeu o nome Satyro de Mello em homenagem ao compositor Paraense Raimundo Satyro de Mello, que nasceu na cidade de Cametá-Pará, onde desde cedo aprendeu a tocar vários estrumemos musicais.

Faleceu em 1957 na cidade do Rio de Janeiro, onde ganhou grande reconhecimento como orquestrador, exatamente por ter a habilidade de transformar para a linguagem musical, as composições de outros autores que não sabiam ler e escrever. Dentre suas músicas mais conhecidas está: O general do samba - sucesso do ano de 1950; A mulher quando não quer; O castigo hás de encontrar. 


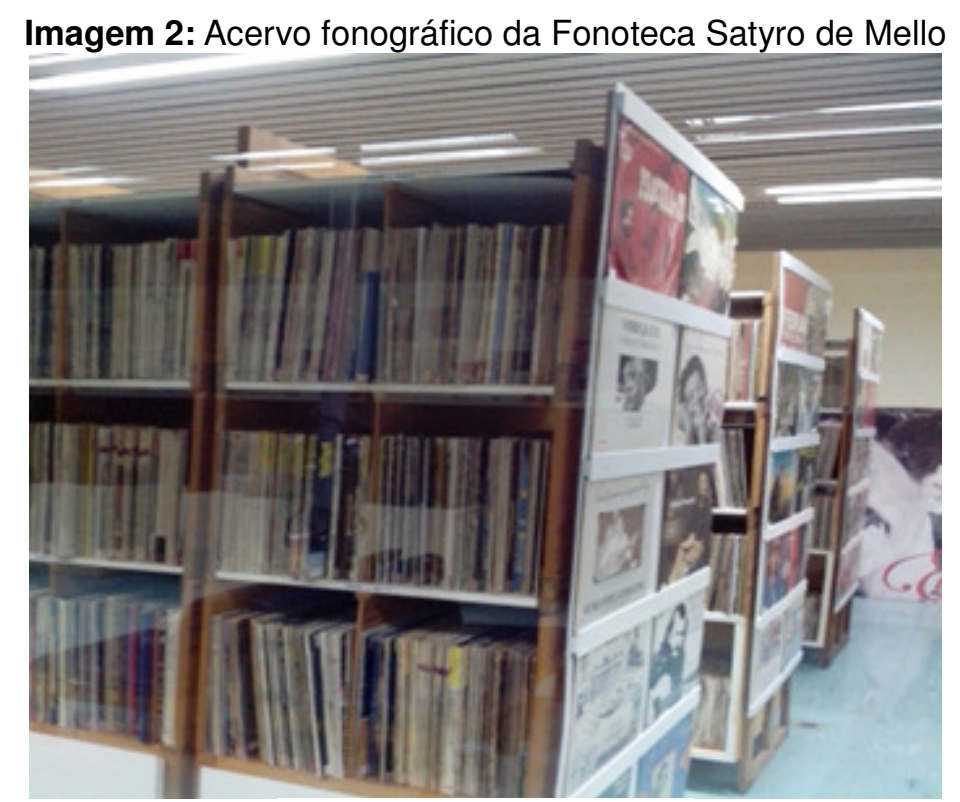

Fonte: Dados da pesquisa.

Deste modo, esclarecemos que o acesso ao acervo é restrito por possuir obras musicais raras, no qual, abriga diferentes estilos musicais do erudito ao popular do internacional ao regional e também sonoridades dos discursos marcantes de líderes políticos como de Getúlio Vargas e Hitler decretando invasão à Polônia.

Possui um pequeno acervo de livros musicais de artistas reconhecidos, dentre estes é possível encontrar biografias de Elis Regina, Vinicius de Moraes, Beatles e o Movimento Tropicália.

Dessa maneira, consideramos que a Fonoteca Satyro de Mello proporciona um ambiente democrático para todos os gostos e públicos musicais, no qual seu público consista em estudantes de música, pesquisadores, músicos regionais, produtores culturais, alunos de escolas etc.

A frequência nesse espaço é de diversos usuários como diferentes objetivos sobre a música, que realizam desde a execução de pesquisas, até a busca por lazer e entretenimento. 
Imagem 3: Catálogo de Discos de Vinil

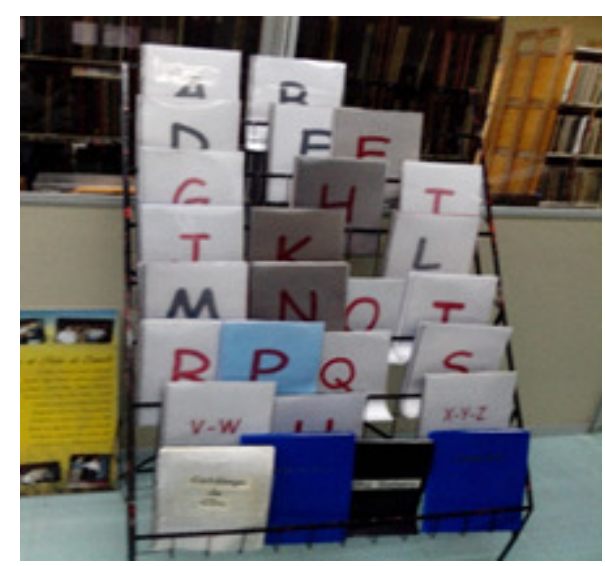

Fonte: Dados da pesquisa.
Imagem 4: Catálogo de Mídias

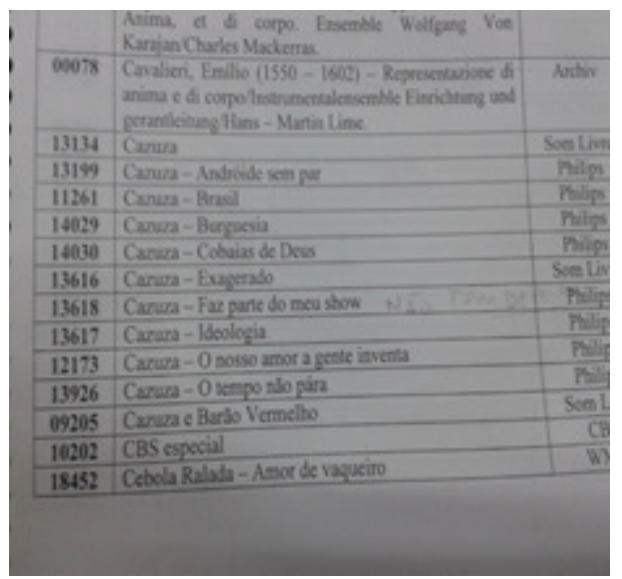

Fonte: Dados da pesquisa.

A Fonoteca oferece serviços didáticos e programas educacionais, como visitas monitoradas, de escolas públicas e particulares que podem ser solicitadas por um formulário e expõem palestras e Wokshops com instrumentistas Paraenses. Do mesmo modo, contam com o projeto "Quarta às Quatro" que é um evento a qual acontece toda última quartafeira do mês, com a participação de artistas da terra que se apresentam, divulgando suas composições, aproximando mais público da cultura Paraense por meio da música.

O ambiente da Fonoteca proporciona uma viagem no tempo desde os primeiros toca-discos ao gramofone, Tv e rádio do século passado. Desta forma, a música encontrar-se em todo o entorno do seu espaço temático, ocasionando um ambiente acolhedor para quem busca informação, história e música ao mesmo tempo.

\section{O BIBLIOTECÁRIO COMO AGENTE MEDIADOR NA FONOTECA}

Tendo um acervo reservado a Fonoteca não possui serviços automatizados, e observando essa questão a pesquisa procurou investigar, de que forma se ocorria a procura e a busca dos vinis no acervo de 35 mil discos. 
Neste caso, esclarecemos que a Fonoteca possui catálogos, manuais impressos em formatos de apostilas, que contém as inicias das letras que remete ao concernente artista e sua classificação, onde é escolhido pelo usuário, e após inquirido pelo Coordenador da Fonoteca João Moreira músico Paraense.

Desta feita a Fonoteca não conta com o apoio do bibliotecário, tendo em vista que os pressupostos desse trabalho é mostra a importância do bibliotecário com agente emancipador no ambiente da Fonoteca.

Neste contexto, destacamos a mediação realizada pelo agente bibliotecário como ato emancipatório na Fonoteca. Uma vez que, a mediação da informação é fator primordial na Fonoteca, visto que, a prática de representação e acesso, à tornaria mais prática na relação entre o suporte de informação e os seus usuários.

Isto é, a liberdade dos atores envolvidos no ambiente da Fonoteca e a mediação sendo pensada como um canal comunicativo de ação emancipatória. Deste modo, a mediação pressupõe uma ação voltada para compreensão.

Assim sendo,

É toda ação de interferência- realizada pelo profissional da informação-direta ou indireta; consciente ou inconsciente; singular ou plural; individual ou coletiva; que propicia a apropriação de informação que satisfaça, plena ou parcialmente, uma necessidade informacional. (ALMEIDA JÚNIOR, 2008, p. 46).

Como em outros ambientes de informação, acreditamos que na Fonoteca o bibliotecário deve possuir as competências comunicativas necessárias para as habilidades do seu cargo. Essas competências, devem buscar:

A qualificação dos cidadãos: em seu poder de informação, em sua capacidade de refletir e de levar em conta as conseqüências de decisões politicamente relevantes, em sua vontade de formular e impor 
interesses levando em conta os interesses de seus concidadãos e das gerações futuras [...]. (HABERMAS, 1990, p. 128).

Com efeito, consideramos que o bibliotecário deve ser conhecedor do seu acervo e das diversas culturas musicais, pois além de oferecer o serviço para os usuários, ele utiliza de seu conhecimento (interdisciplinar) sobre o acervo para indicar os discos e tirar as dúvidas de seus usuários, "[...] o que se quer trazer à luz é o campo epistemológico, a epistémê onde os conhecimentos, encarados fora de qualquer critério referente a seu valor racional ou a suas formas objetivas." (FOUCAULT, 1999, p. 18).

Desta forma, como agentes da informação:

Os bibliotecários não podem oferecer uma visão dos sistemas de organização do conhecimento isolados das estruturas de comunicação totais da sociedade. A prática da biblioteconomia precisa ser condicionada por um entendimento de como o conhecimento e documentos são organizados socialmente, porque essa organização social estrutura e influencia as possibilidades de organização do conhecimento. (ANDERSEN, 2005, p. 18).

Assim, se constitui a prática a competência comunicativa que o bibliotecário de deve possuir, como "[...] conhecer o acervo [...] ser um bom comunicador e ser um agente cultural." (SILVA, 2005, p. 38). Deste modo, "[...] o bibliotecário de referência deve ter curiosidade, agilidade mental para analisar o enfoque de uma consulta, deve também possuir cultura geral [...]" (THOPSEM, 1999 apud VEGA, 2000).

Por conseguinte, colocamos que essas habilidades foram sintetizadas, uma vez que com a carência do bibliotecário de referência no ambiente da Fonoteca, há um aprovisionamento de competências, visto que ele deve possuir o domínio cultural sobre a história musical e os seus respectivos acontecimentos e isto é crucial para a mediação e apropriação da informação na Fonoteca. 
Como exposto, na pesquisa, através da representação do seu acervo fonográfico, por meio dos vinis e ao mesmo tempo da representação da história referente à música registrada no suporte. Situamos ser possível contextualizar o bibliotecário frente o acervo histórico de vinis e sua organização.

Segundo Deleuze e Guattari (2000, p. 54):

Assim como na música, o princípio de organização ou de desenvolvimento não aparece por si mesmo em relação direta com aquilo que se desenvolve ou se organiza: há um princípio composicional transcendente que não é sonoro, que não é "audível" por si mesmo ou para si mesmo. Isto permite todas as interpretações possíveis. As formas e seus desenvolvimentos, os sujeitos e suas formações remetem a um plano que opera como unidade transcendente [...].

De modo crítico e interpretativo expomos as várias possibilidades de caminhamos para o conhecimento musical. Assim sendo, consideramos que o bibliotecário é um mediador de ações na Fonoteca, uma vez que analisamos que o conhecimento que está no âmbito na Fonoteca procede de ações coletivas emancipatórias, pois, além do bibliotecário mediar a informação, ele agrega valor cultural para os usuários utilizarem dos seus serviços e pôr em debate o conhecimento musical.

Portanto, essa é uma prática defendida por Melo e Vieira (2012, p. 6) que abordam que

Não somos apenas mediadores entre o saber e quem o busca, somos também um propagador do saber, da cultura, e responsáveis por disseminar e difundir 0 conhecimento nas comunidades, instituições e organizações em que participamos ou trabalhamos.

Desta forma, situamos de forma prática os caminhos do conhecimento musical na Fonoteca Satyro de Mello na qual organiza os discos de vinis, de modo a proporcionar a melhor forma de mediar por meio desses suportes sonoros, os conhecimentos e acontecimentos 
históricos como: a primeira apresentação de O Guarani de Carlos Gomes na Itália; Discurso de Hitler a invasão da Polônia; Trechos da ópera Tiradentes de 1946 e Disco de Chopin e etc.

Da mesma forma, consideramos ser imprescindível que o bibliotecário conheça o seu acervo parar indicar as fontes informativas musicais que se encontram nos variados discos para o seu público-alvo e sua diversidade musical, quanto fazer o resgate do conhecimento cultural e histórico resultando em práticas de sua especificidade no contexto musical, no qual é ressaltado por Silva (2005, p. 133), que o bibliotecário "[...] deve gostar de música e ter sólidos conhecimentos sobre a história e o repertório dos principais cantores e grupos musicais nacionais e internacionais, além de conhecer os principais estilos musicais."

E desta forma, acabará acontecendo ações coletivas emancipatórias do conhecimento com atos dos próprios usuários satisfeitos que além de utilizarem do conhecimento da Fonoteca, recebem-lhe como entretenimento onde agregam 0 valor cultura Regional e Nacional.

\section{CONSIDERAÇÕES FINAIS}

Diante do olhar interpretativo, sobre música como representação informativa analisamos que ela está inserida nos diversos suportes. Deste modo, consideramos ser interessante o trabalho de preservação de documentos sonoros, que é desenvolvido pela Fonoteca Satyro de Melo. Como apresentamos, o bibliotecário é imprescindível nesse âmbito, pois desligar-se da concepção da preservação dos livros (ação técnica). Tendo em vista, que é uma prática totalmente diferente, sua representação segue através de um acervo com discos organizados e que são guardados, valores culturais e históricos, que acrescentam além do teor prático de ouvir músicas, um diálogo possível de um conhecimento. 
Deste modo, esclarecemos que ao visitar a Fonoteca os estudantes do Curso de Biblioteconomia da Universidade Federal do Pará, receberam uma gama de cultura e aprendizagem através do espaço da Fonoteca Satyro de Mello. Contextualizamos, que a figura do Bibliotecário é imprescindível na Fonoteca embora, foi observado sua ausência no ambiente. Pois, deste modo consideramos o Bibliotecário um agente indispensável e seguro com o seus usuários e acervo.

Porquanto, além de apresentar o acervo entendemos que este profissional deve agregar valor cultural aos seus usuários, uma vez que música é um fator de linguagem e compreendimento, um modo de pensamento e ação, quando ouvidas carregavam em si uma compreensão que se volta história ou até mesmo uma singularidade de um acontecimento.

A rigor, o estudo buscou relatar a importância da Fonoteca Satyro de Mello e o bibliotecário como agente mediador, neste sentido a Fonoteca necessita de um profissional da informação que organize a partir da ideia de mediar e disseminar culturalmente e trabalhe em cima de sua competência comunicativa, para alcançar os usuários e levá-los ao entendimento de forma dialogal.

Desta forma, o bibliotecário precisa estar inteirado com o conhecimento no ambiente onde está inserido, ou seja, deve procurar conhecimentos museológicos, que demostrem a promoção do seu espaço profissional, isto é, mostrando a importância de seu conteúdo seja ele sonoro visual ou literal.

Assim, concluímos que a aprendizagem através da música é possível e o espaço da Fonoteca Satyro de Mello, emancipa este aprendizado, oferecendo seus serviços e ações culturais. Por conseguinte, consideramos que é importante que o profissional da informação, busque a dinâmica do seu ambiente de trabalho, levando novidades aos seus usuários mostrando que o profissional além de desenvolver suas competências de mediador é determinado e criativo na utilidade da unidade de informação frente à sociedade. Sendo um 
agente de valor cultural no qual pratica o seu diferencial para seus usuários.

\section{REFERÊNCIAS}

ALMEIDA JÚNIOR, Oswaldo Francisco de. Mediação da informação: ampliando o conceito de disseminação. In: VALETIM, Marta Lígia Pomim. (Org.). Gestão da informação e do conhecimento. São Paulo: Polis; Cultura Acadêmica, 2008. p. 41-54.

ANDERSEN, Jack. Information criticism: where is it? Progressive librarian, v. 25, 2005. Disponível em:

<http://libr.org/pl/25_Andersen.html>. Acesso em: 03 nov. 2015.

AQUINO, Mirian de Albuquerque de; SILVA JÚNIOR, Jobson Francisco. A informação no Funk: construindo a identidade afrodescendente.

Revista Biblionline, João Pessoa, v. 8, n. esp., 2012. Disponível em: <http://periodicos.ufpb.br/ojs/index.php/biblio/article/view/14212/8121>. Acesso em: 11 nov. 2015.

BARROS, Camilla Monteiro de. Cultura, informação e sociedade: o espaço da música no desenvolvimento e gestão de coleções. 2006. 49 f. Trabalho de conclusão de curso (Graduação em Biblioteconomia Gestão da informação) - Universidade do Estado de Santa Catarina, Florianópolis, 2006.

BLACKING, John. Música, cultura e experiência. Cadernos de Campo (São Paulo, 1991), Brasil, v. 16, n. 16, p. 201-218, mar. 2007. Disponível em: <http://www.revistas.usp.br/cadernosdecampo/article/view/50064/55695 >. Acesso em: 14 out. 2015.

. The problem of "ethnic" perceptions in the semiotics of music. In: STEINER, W. (Ed.). E sign inmusic and literature. Austin: University of Texas Press, 1981.

DELEUZE, Gilles. Conversações. Rio de Janeiro: Editora 34, 1992.

DELEUZE, Gilles; GUATTARI, Félix. Mil platôs-vol. 4. São Paulo: Editora 34, 2000.

O Anti-Édipo Capitalismo e Esquizofrenia - vol. 1. Lisboa: Assírio e alvim, 2004. 
FOUCAULT, Michel. As palavras e as coisas: uma arqueologia das ciências humanas. São Paulo: Martins Fontes, 1999.

GIL, Antonio Carlos. Como elaborar projetos de pesquisa. São Paulo: Atlas, 2002.

HABERMAS, Jürgen. Conhecimento e interesse. Rio de Janeiro: Zahar, 1987.

1993.

Passado como Futuro. Rio de Janeiro: Tempo Brasileiro, Brasileiro, 1990.

Pensamento Pós-metafísico. Rio de Janeiro: Tempo

HOUAISS, Antônio. Minidicionário Houaiss da língua Portuguesa. Rio de Janeiro: Objetiva, 2010.

LE COADIC, Yves-François. A Ciência da Informação. Brasília: Briquet de Lemos, 1996. 117p.

MARCONI, Marina de Andrade; LAKATOS, Eva Maria. Fundamentos da metodologia científica. São Paulo: Atlas, 2006.

MELO, Priscilla; VIEIRA, Ronaldo. O bibliotecário como agente cultural. São Paulo: Agbook, 2012. Disponível em: <http://www.youblisher.com/p/519493-O-BIBLIOTECARIO-COMOAGENTE-CULTURAL/>. Acesso em: 18 nov. 2015.

MIRANDA, Silvânia. Como as necessidades de informação podem se relacionar com as competências informacionais. Revista Ciência da Informação, Brasília, v. 35, n. 3, p. 99-114, set./dez. 2006. Disponível em: <http://www.scielo.br/pdf/ci/v35n3/v35n3a10.pdf>. Acesso em: 24 nov. 2015.

NIETZSCHE, Friedrich Wilhelm. O crepúsculo dos ídolos ou a filosofia a golpes de martelo. Paraná: Hemus, 2001.

NÖTH, Winfried. Panorama da semiótica - de Platão a Peirce. São Paulo: Annablume, 1995.

OLIVEIRA, Marlene de. Origens e Evolução da Ciência da Informação. In:__ (Org.). Ciência da Informação e Biblioteconomia: novos conteúdos e espaços de atuação. Horizonte: UFMG, 2005.

ONGARO, Carina de Faveri; SILVA, Cristiane de Souza; RICCI, Sandra Mara. A importância da música na aprendizagem, [s.l], 2006.

Disponível em: <http://www.meloteca.com/musicoterapia2014/aimportancia-da-musica-na-aprendizagem.pdf>. Acesso em: 10 nov. 2015. 
QUEIRÓZ, Maria Isaura Pereira. O pesquisador, o problema da pesquisa, a escolha de técnicas: algumas reflexões. In: LANG, Alice Beatriz da Silva Gordo (Org.). Reflexões sobre a pesquisa sociológica. São Paulo: CERu, 1992, p. 13-19.

SILVA, Fabiano Couto Corrêa da. Bibliotecários especialistas: guia de especialidades e recursos informacionais. Brasília: Thesaurus, 2005.

SILVA, Rociclei da; ALBAGLI, Sarita. Arte, informação e conhecimento na cultura Hip Hop. Revista Tendências da Pesquisa Brasileira em Ciência da Informação, v. 5, n. 1, 2012. Disponível em: $<$ http://inseer.ibict.br/ancib/index.php/tpbci/article/view/69/111>. Acesso em: 10 nov. 2015.

VALENTE, Heloísa de Araújo Duarte. Música é informação: música e mídias a partir dos conceitos de R. Murray Schafer e Paul Zumthor. In: SILVA, Rafael Souza (Org.). Discurso simbólico da mídia. São Paulo: Loyola, 2005.

VEGA, José Antonio Merlo. El serviço bibliotecário de referência. Anales de Documentación, Salamanca, n. 3, 2000.

\section{Title}

The Music as Representative Source Information: the Case of Fonoteca Satyro de Mello on Centur / Fcptn

\section{ABSTRACT}

Introduction: To consider the music as interpretative source of information.

Objective: Discusses the importance of music as representative aspect in Fonoteca Satyro Mello and as social and informational process.

Methodology: This is an exploratory research of bibliographic and documentary basis.

Discussions: Presents the Fonoteca Satyro Mello as an instrument of cultural representation and the music as a source on the social context information librarian.

Conclusions: Terminates the experience reporting librarian must have to play its role of mediator and cultural agent in Fonoteca Satyro Mello.

Keywords: Fonoteca. Music. Culture. Information. Librarian.

\section{Título}

Música como fuente de información de representante: el caso de Satyro Fonoteca de Mello en Centur Fcptn 


\section{RESUMEN}

Introducción: Considerar la música como fuente interpretativa de la información.

Objetivo: Analiza la importancia de la música como aspecto representativo en Fonoteca Satyro Mello y como proceso social y de información.

Metodología: Se trata de una investigación de base documental y bibliográfica.

Discusiones: Presenta la Fonoteca Satyro Mello como instrumento de representación cultural y la música como una fuente en el bibliotecario de la información de contexto social.

Conclusiones: Termine la experiencia informes bibliotecario debe tener para desempeñar su papel de mediador y agente cultural en Fonoteca Satyro Mello.

Palabras clave: Fonoteca. Música. Cultura. Información. Bibliotecario.

Recebido em: 26.12 .2015

Aceito em: 20.03.2016 